\title{
The greek version of the resilience scale (rs- I4): psychometric properties in three samples and associations with mental illness, suicidality, and quality of life
}

\begin{abstract}
Background: Resilience is defined as the capacity to successfully maintain or regain mental health and well-being in the face of significant adversity or risk. The Wagnild and Young Resilience Scale-14 (RS-14) is a brief measure assessing resilience. We aimed to assess the psychometric properties of its Greek version in three samples, people with longterm conditions (LTCs) attending the emergency department, people with LTCs attending specialty clinics and people without LTCs. Associations between resilience and mental illness, suicidality, and quality of life were also investigated.
\end{abstract}

Methods: The RS-14 was administered to 495 participants; 366 patients with diabetes, chronic pulmonary obstructive disease (COPD) and rheumatic diseases attending either the emergency department $(\mathrm{N}=74)$ or specialty clinics $(\mathrm{N}=292)$ and 129 individuals without LTCs. Diagnosis of mental disorders was established by the Mini International Neuropsychiatric Interview (MINI). Associations with depressive symptom severity (PHQ9), suicidal risk (RASS), and health-related quality of life (WHOQOL-BREF) were also investigated.

Results: The Greek version of RS-14 showed a coherent one-dimensional factor structure with remarkable stability across the three samples. Cronbach's alphas were $0.88-0.91$ across the three samples, being 0.89 for the entire sample. Furthermore, greater RS-14 scores were associated with better mental health, lower depressive symptom severity and suicidal risk and better health-related quality of life and satisfaction with general health.

Conclusion: The results of the present study showed that the Greek version of RS-14 may reliably assess resilience. In addition, lower levels of resilience are associated with established mental disorders and increased suicidal risk, and thus may detrimentally impact mental health. These findings deserve replication in prospective studies.

Keywords: resilience, rs-14, chronic illness, mental illness, suicidality, quality of life
Volume 7 Issue 5 - 2017

Elisavet Ntountoulaki,' Vassiliki Paika,' Konstantinos Kotsis,' Dimitra Papaioannou,' Elias Andreoulakis, ${ }^{2}$ Konstantinos N Fountoulakis, ${ }^{2}$ Andre F Carvalho, ${ }^{3}$ Thomas Hyphantis'

'Department of Psychiatry, Faculty of Medicine, University of loannina, Greece

${ }^{2}$ Third Department of Psychiatry, School of Medicine, Aristotle University of Thessaloniki, Greece

${ }^{3}$ Department of Clinical Medicine and Translational Psychiatry Research Group, Faculty of Medicine, Federal University of Cear?, Brazil

Correspondence: Thomas Hyphantis, Professor of Psychiatry, Department of Psychiatry, Faculty of Medicine, School of Health Sciences University of loannina, loannina 45 I I0, Greece, Tel 30 26510 07322,Email tyfantis@cc.uoi.gr

Received: March 09, 2017 | Published: March 22, 2017
Abbreviations: LTCs, long-term conditions; DM, type-ii diabetes mellitus; RD, rheumatological disorders; COPD, chronic pulmonary obstructive disease; MDD, major depressive disorder; $\mathrm{GAD}$, generalized anxiety disorder; RS, resilience scale (original); RS-14, resilience scale-14 (abbreviated version); MINI, mini international neuropsychiatric interview; PHQ-9, patient health questionnaire-9; RASS, risk assessment suicidality scale; HRQoL, health-related quality of life

\section{Introduction}

People facing major adverse life events such as a disaster, a physical illness or a specific stressor can display a wide range of responses, from adaptive to maladaptive ones. Their coping abilities as well as their psychological resources to deal with the stressor could shape those responses. Resilience may constitute a key element in this respect, with regard to the way a person will respond during and after the occurrence of an adverse life event. ${ }^{1-5}$ Although a consensual definition of resilience is lacking, it has been widely defined as the capacity to successfully maintain or regain mental health and wellbeing in the face of significant adversities, with the allocation of internal and environmental resources, and by negotiating or managing significant sources of stress and trauma. ${ }^{6-8}$ It is an interactive dynamic process that may promote psychological and physical well-being. . $^{2,3}$ In health research, resilience also refers to the process of effectively adapting to stressful situations such as a chronic illness, and resist to maladaptation in the face of health-risky experiences. ${ }^{3,9}$

The importance of resilience to a person's mental and physical health has been increasingly recognized, and research efforts have been directed to the assessment of this construct. Resilience has been found to positively correlate with physical health, self-efficacy, gratitude, optimism, physical and emotional wellness, and positive effect, and to negatively correlate with depression, generalized anxiety disorder and posttraumatic stress disorder. ${ }^{10-15}$ Studies in cancer samples also showed that resilience promotes positive adaptation and may also enhance physical, social and emotional aspects of quality of life. ${ }^{16,17}$ Furthermore, emerging evidence indicates that resilience could partially mediate the relationship of psychological stress with depressive and anxiety symptoms. ${ }^{18}$ As research on resilience continues to grow during the last decade, it is essential to have brief, reliable and valid assessment measures of resilience for a range of populations. 5,7

A number of scales have been developed to measure resilience, including but not limited to the Connor-Davidson Resilience Scale, ${ }^{19}$ 
the Resilience Attitudes and Skills Profile,$^{20}$ the Resilience Scale for adults, ${ }^{21}$ and the Brief Resilience Scale, ${ }^{22}$ among others. ${ }^{23}$ However, there is no consensus about a generally accepted scale that could have the most adequate psychometric properties. ${ }^{19}$ Wagnild \& Young ${ }^{24}$ developed the 25-item Resilience Scale (RS), which attracted much attention and has been used in a number of studies, ${ }^{23}$ it has been also regarded as an adequate instrument for assessing resilience in adolescent samples. ${ }^{25}$ An abridged 14-item version of RS (RS-14) comprising items of the original RS scale has been developed, ${ }^{26}$ which assesses the five core characteristics of resilience namely selfreliance, purpose in life, equanimity, perseverance, and authenticity. This "Resilience Core" includes an inter-related combination of protective factors that provide an adequate adaptation to stress, which may result in better outcomes after exposure to adverse situations throughout the lifespan. ${ }^{26-28}$

The RS-14 has been either translated across several different languages including Arabic, English, Greek, Russian, Spanish, and Swedish, among others. ${ }^{29}$ Moreover, independent studies have used its English, ${ }^{5}$ Brazilian, ${ }^{11}$ Chinese, ${ }^{17}$ Japanese,${ }^{30}$ Taiwanese ${ }^{31}$ and Korean versions. ${ }^{32}$ RS-14 scores have been found to be positively associated with psychological well-being, purpose in life, self-esteem, social support, quality of life, and self-reported good health status. ${ }^{5,26,27,33,34}$ Conversely, RS-14 scores seem to be negatively correlated with depression, anxiety, stress, posttraumatic stress disorder, and disability., ${ }^{411,26,27,30}$ This instrument has also been administered to adolescents, ${ }^{35}$ college and university students, ${ }^{30,36}$ and cancer patients. ${ }^{17}$ However, additional studies in specific populations would provide a better appreciation of the psychometric properties of the RS-14 instrument, especially as far as its association with established mental disorders and other relevant parameters, such as suicidal risk in both health and disease. Prompted by this fact, the aim of the present study is to examine the psychometric properties of the Greek version of the RS-14 scale in three different samples:

a. Patients with long-term conditions (LTCs) seeking urgent or unscheduled care in the emergency department,

b. Patients with LTCs attending specialty clinics, and

c. People without LTCs. Furthermore, we aimed to assess its convergence and concurrent validity by analyzing associations with established mental disorders, depressive symptom severity, suicidal risk and health-related quality of life (HRQoL).

\section{Methods}

\section{Participants}

Data were collected during the baseline assessment of the cohort study "Assessing and enhancing resilience to depression in people with long term medical conditions in the era of the current Greek social and financial crisis". This research has been co-financed by the European Economic Area (EEA) Financial Mechanism 2009-2014 and National funds as part of the program "Dissimilarity, Inequality and Social Integration", and its main objective is to develop psychosocial strategies to enhance resilience to depression in most affected by the current Greek social and financial crisis vulnerable patients with LTCs, through a program of applied clinical research.

Of a total number of 505 adults participated in the study, 495 completed the RS-14 scale and thus were included in the present report. The sample comprised 366 patients with LTCs and 129 individuals without LTCs. The patient sample comprised patients with at least one of three LTCs: type-II diabetes mellitus (DM), rheumatological disorders (RD) and chronic pulmonary obstructive disease (COPD) who were seeking unscheduled or urgent care at the emergency department (ED) of the University Hospital of Ioannina $(\mathrm{N}=74)$ or were attending routine care in the respective follow-up specialty clinics $(\mathrm{N}=292)$ during a six-month period. These three conditions are among the leading 15 discharge diagnoses of emergency departments ${ }^{37}$ and are associated with an increased risk of an emergency hospital admission during the subsequent 6 month periods ${ }^{38}$ Exclusion criteria were: inability to read and write Greek, mental retardation, active psychosis, state of intoxication or confusion, or being severely unwell physically to respond to the study's questionnaires.

Of 116 patients who were approached in the ED, 86 were eligible and 74 agreed to participate (response rate $86.1 \%$ ); 33 with DM only, 5 with RD only, 22 with COPD only and 14 with a combination of conditions. Ages ranged from 18 to 94 years (mean, 66.2; SD, 14.7); 43 were males $(58.1 \%)$ and 31 females (41.9\%). Of 360 patients attending specialty clinics who were approached, 350 were eligible and 302 agreed to participate (response rate $86.3 \%$ ); 88 with DM only, 172 with RD only, 7 with COPD only, and 35 with a combination of conditions. Ages ranged from 20 to 88 years (mean, 59.4; SD, 14.0); 157 were males (52.0\%) and 145 females (48.0\%). Ten patients $(3.3 \%)$ did not complete the RS-14 and were excluded from the present study, thus 292 patients attending specialty clinics were included in the analyses of the current study. People without LTCs were recruited from the hospital staff. Healthcare workers in all hospital's departments and clinical units were invited to participate. Exclusion criterion was a self-reported LTC (i.e. DM, RD or COPD). Two hundred and twenty potential participants were approached, 200 were eligible and 129 agreed to participate (response rate 64.5\%). Ages ranged from 20 to 58years (mean, 39.5; SD, 10.7); 32 were males $(24.8 \%)$ and 97 females $(75.2 \%)$. No statistically significant differences were found in age, sex, education and marital status between participants and nonparticipants as well as between those who had completed the RS-14 and those who did not provide complete responses to this instrument across all samples (data available upon request).

Researchers were in the hospital from 8.00 a.m. to 4.00 p.m. every day and participants were consecutively recruited during this time frame. Participants of either gender aged $\geq 18$ years old were considered for inclusion and, for patients, a diagnosis of DM, RD or COPD was confirmed by the attending physician. Three trained research psychologists (EN, VP, and DP) collected the data. The interviewers had at least 4 years of research and clinical experience at the Department of Psychiatry of the University of Ioannina and were also trained on the administration of diagnostic instruments and screens. The interviewers were blind to scores of the self-report questionnaires, which were administered on the same day. All study procedures were in accordance with the World Medical Association Helsinki Declaration. The study was approved by the hospital's ethics committee (617/17-09-2015). Signed informed consent was obtained from all participants.

\section{Measures and study instruments}

Socio-demographic variables including age, sex, educational level, marital status, residence, employment status and occupation were collected for all participants. For patients with LTCs clinical features, disease severity indices and laboratory data were obtained from patients' records using a standardized data collection form. Coexisting medical diseases were scored using the Charlson comorbidity scale, ${ }^{39}$ which is one of the most extensively validated comorbidity indices.

Resilience was assessed using the Greek version of the 14-item 
Wagnild and Young Resilience Scale-14 (RS-14) ${ }^{24}$ after licensing. RS-14 is 7-point Likert-type scale and scores range from 1 (strongly disagree) to 7 (strongly agree); sum score range from 14 to 98 . Higher scores indicate stronger resilience. Scores greater than 90 indicate high resilience, 82-90 moderately high, 65-81 moderately low to moderate, 64 to 57 low, and scores below than 56 indicate very low resilience. ${ }^{26}$ The psychometric properties of the scale have been extensively tested in a number of studies across several samples and languages and principal component analyses revealed a single-factor solution with Cronbach's alpha coefficients ranging from 0.72 to 0.94 , supporting the internal consistency reliability of the RS-14. ${ }^{27}$

Diagnoses of mental disorders were established using the Greek version 5.0.0 of the Mini International Neuropsychiatric Interview (MINI) ${ }^{40}$ The MINI is a structured psychiatric interview that ascertains the diagnosis of mental disorders according to DSM-IV or ICD-10 criteria. ${ }^{41}$ It focuses mainly on current diagnosis and contains 120 questions for screening 17 axis I disorders. Being fully structured to allow administration by clinicians after a brief training session, it was designed to meet the need for a short but valid psychiatric interview for epidemiology studies. ${ }^{41}$ MINI has been previously used in studies with Greek medical patients. ${ }^{42,43}$

Depressive symptom severity was assessed using the validated Greek version of the Patient Health Questionnaire-9 (PHQ-9). ${ }^{42,44}$ This instrument screens for DSM-IV major depressive disorder. The frequency of symptoms over the past 2 weeks is rated on a 0-3 Likert-type scale; summed scores range from 0 to 27 . Higher scores indicate more severe symptoms. It has been translated into numerous languages including Greek and is considered a valid measure of depressive symptom severity. ${ }^{42,45}$ Cronbach's alpha for PHQ-9 derived from the present sample was 0.83 .

Suicidal risk was assessed using the standardized Greek version of the Risk Assessment Suicidality Scale (RASS) ${ }^{46}$ RASS is a brief 12-item self-report instrument assessing suicidal risk behaviours and contains items relevant to intention, life, and history of suicide attempts. Items are rated on a 0-3 Likert-type scale (not at all to very much) and the scores were transformed according to the suggestions of the standardization study for use within the Greek population. ${ }^{46}$ In patients with LTCs attending the ED Cronbach's alpha for the RASS was 0.80 and alpha derived from the present sample was $0.77 .{ }^{47}$ Higher scores indicate greater suicidal risk.

Health-related quality of life (HRQoL) was assessed using the 26item validated Greek version of the World Health Organization Quality of Life Instrument, Short Form (WHOQOL-BREF) ${ }^{48}$ It assesses six domains of HRQoL, overall HRQoL, satisfaction with general health, physical, mental, social relations and environment HRQoL. Each item is rated on a 5-point Likert scale, and the scores are transformed on a scale from 0 to 100 . Higher scores indicate better HRQoL.

\section{Statistical analysis}

All analyses were performed using the Statistical Package for the Social Sciences (SPSS) version 21.0 (SPSS Inc., Chicago, IL, USA) for Windows. Summary statistics for all variables were calculated. Normality was tested by the Kolmogorov-Smirnov test. ${ }^{49}$ To test whether the RS-14 items gather in clusters and to assess the stability of its factorial structure across the 3 samples, principal component factor analyses (PCA) with varimax rotation were performed separately for each sample as well as in the total sample. Internal consistencies (Cronbach alphas) were next calculated for the factors derived from the PCA.
The criterion and concurrent validity was tested with the following hypotheses in mind:

a. Resilience is associated with measures of positive psychological constructs, such as depression, anxiety, and stress., , 11,27,30 $^{2}$ Accordingly, RS-14 score should be negatively associated with a diagnosis of mental disorder. For this, two tailed t-tests were performed to assess the differences in RS-14 scores between those diagnosed with a mental disorder and those who didn't. To quantify the differences, simple logistic regression analyses were next performed with dependent variable the specific mental diagnosis and independent variable the RS-14 score. In addition, to assess the relationship of RS-14 with depressive symptom severity as assessed with the PHQ-9, bivariate correlation analyses were performed followed by partial correlation analyses adjusted for age, sex, education, family status, disease type and comorbidities;

b. Resilience is associated with lower suicide risk. ${ }^{50-53}$ To assess the relationship between RS-14 scores and RASS scores bivariate correlation analyses were performed followed by partial correlation analyses adjusted for age, sex, education, family status, disease type and comorbidities;

c. Resilience is associated with better wellbeing, satisfaction with health and health-related quality of life. ${ }^{5,27,33,34}$ Accordingly, RS14 scores should be positively associated with WHOQOL-BREF scores. To test this, bivariate correlation analyses were performed followed by partial correlation analyses adjusted for age, sex, education, family status, disease type and comorbidities.

\section{Results}

\section{Factor structure}

Four independently produced principal component exploratory factor analyses were performed for the total sample and for each one group of participants, i.e. the healthy participants sample, the attending the ED medical patient sample and the routine care medical patient sample. Principal component analyses across the four groups showed Kaiser-Mayer-Olkin statistics of $0.921,0.916,0.839$, and 0.892 respectively; all Bartlett's tests were significant for sphericity $\left(\mathrm{x}^{2}=2660.5, \mathrm{df}=91, \mathrm{p}<0.001 ; \mathrm{x}^{2}=877.4, \mathrm{df}=91, \mathrm{p}<0.001 ; \mathrm{x}^{2}=752.1\right.$, $\mathrm{df}=91$; and $\mathrm{x}^{2}=1429.0, \mathrm{df}=91, \mathrm{p}<0.001$, respectively), supporting the factorability of the correlation matrices. An inspection of the screen plot in the total sample (Figure 1) as well as in all three groups of participants (data available upon request) revealed a large component and a number of "elbows" resulting in small eigenvalues after the first component, revealing the presence of a coherent unidimensional structure (Table 1). As shown in Table 1, all items loaded saliently on this factor, with item loading ranged between 0.541 and 0.779 in the total sample, confirming the coherent structure of this version of the instrument. Similar results were observed regarding the item loadings across the three samples, with the exception of items 9 ("I keep interested in things") and 10 ("I can usually find something to laugh about") that present somewhat lower ( 0.410 and 0.428 , respectively) but still significant loadings in the ED sample (Table 1).

\section{Internal consistency, total scores and scoring categories across the three samples}

As shown in Table 2, Cronbach's alphas ranged between 0.88 and 0.91 across the three samples, and alpha for the total sample was 0.89 . Mean scores of RS-14 was lower for patients with LTCs attending the ED compared to participants without LTCs ( $\mathrm{p}=0.021$ ), (Table 2). 
Table 3 presents the distribution of RS-14 categories suggested in the original version. ${ }^{26}$ As shown in this Table, there is a tendency for more people without LTCs to present "moderately high" and "high" resilience compared to both patient groups, but the differences failed to reach statistical significance. Mean rates of RS-14 did not differ significantly across gender $(\mathrm{p}=0.984)$ and marital status $(\mathrm{p}=0.704)$; the better the education received the stronger the resilience $(\mathrm{r}=0.151$, $\mathrm{p}=0.002$ ) while older people tended to report higher resilience scores, although the correlation coefficient failed to reach statistical significance $(\mathrm{p}=0.070)$.

\section{Resilience and mental illness}

Two hundred and one $(40.6 \%)$ participants were diagnosed with a mental disorder, 111 (22.4\%) with major depressive disorder (MDD), $76(15.3 \%)$ with generalized anxiety disorder (GAD) and $27(5.5 \%)$ with panic disorder. As shown in Table 4, people diagnosed with any mental illness, either MDD, panic disorder or GAD, presented lower scores in RS-14 compared to those without a mental disorder. The binary logistic regression analyses performed to quantify the differences confirmed these associations (Table 4).

\section{Resilience and depressive symptom severity, suicidal risk, and HRQoL}

Table 5 presents the results of the unadjusted and adjusted (partial) correlation analyses performed to assess the associations of RS14 with PHQ-9, RASS, and WHOQOL-BREF scores. As shown in this table, both unadjusted and adjusted scores of RS-14 were significantly associated with depressive symptom severity, suicidal risk, and HRQoL. The higher the resilience the lower the depressive symptom severity and suicidal risk; also, the higher the resilience the better the overall HRQoL, satisfaction with general health, as well as the physical, mental, social relations and environment HRQoL.

Table I Factor loadings of the Greek version of the Resilience scale (RS-I4) in three different samples

\begin{tabular}{|c|c|c|c|c|}
\hline & $\begin{array}{l}\text { Total } \\
\text { Sample } \\
(\mathbf{N}=495)\end{array}$ & $\begin{array}{l}\text { Participants } \\
\text { without } \\
\text { LTCs } \\
(\mathrm{N}=129)\end{array}$ & $\begin{array}{l}\text { Patients with } \\
\text { LTCs Attending } \\
\text { the Emergency } \\
\text { Department }(\mathbf{N}=\mathbf{7 4})\end{array}$ & $\begin{array}{l}\text { Patients with } \\
\text { LTCs Attending } \\
\text { Specialty Clinics } \\
(\mathrm{N}=292)\end{array}$ \\
\hline Item I - I usually manage one way or another & 0.656 & 0.64 & 0.862 & 0.64 \\
\hline Item 2 - I feel proud that I have accomplished things in life & 0.593 & 0.533 & 0.795 & 0.533 \\
\hline Item 3 - I usually take things in stride & 0.609 & 0.585 & 0.679 & 0.585 \\
\hline Item 4 - I am friends with myself & 0.634 & 0.622 & 0.565 & 0.622 \\
\hline Item 5 - I feel that I can handle many things at a time & 0.7 & 0.7 & 0.57 & 0.7 \\
\hline Item 6 - I am determined & 0.626 & 0.584 & 0.694 & 0.584 \\
\hline $\begin{array}{l}\text { Item } 7 \text { - I can get through difficult times because I've } \\
\text { experienced difficulty before }\end{array}$ & 0.62 & 0.609 & 0.728 & 0.609 \\
\hline Item 8 - I have self-discipline & $0.54 I$ & 0.505 & 0.594 & 0.505 \\
\hline Item 9 - I keep interested in things & 0.61 & 0.565 & 0.41 & 0.565 \\
\hline Item I0 - I can usually find something to laugh about & 0.642 & 0.66 & 0.428 & 0.66 \\
\hline Item II - My belief in myself gets me through hard times & 0.771 & 0.761 & 0.807 & 0.761 \\
\hline $\begin{array}{l}\text { Item I } 2 \text { - In an emergency, I'm someone people can generally } \\
\text { rely on }\end{array}$ & 0.609 & 0.543 & 0.706 & 0.543 \\
\hline Item I3 - My life has meaning & 0.707 & 0.671 & 0.884 & 0.671 \\
\hline $\begin{array}{l}\text { Item I4 - When I'm in a difficult situation, I can usually find my } \\
\text { way out of it }\end{array}$ & 0.779 & 0.745 & 0.907 & 0.745 \\
\hline$\%$ of Variance & 42.6 & 48.9 & 49.6 & 39.4 \\
\hline
\end{tabular}

Table 2 Internal consistency coefficients and RS-14 total scores across the three samples

\begin{tabular}{lllll}
\hline & $\begin{array}{l}\text { Total } \\
\text { sample } \\
(\mathbf{N}=\mathbf{4 9 5})\end{array}$ & $\begin{array}{l}\text { Participants } \\
\text { without LTCs } \\
\mathbf{( N = 1 2 9 )}\end{array}$ & $\begin{array}{l}\text { Patients with LTCs } \\
\text { attending the Emergency } \\
\text { Department (N=74) }\end{array}$ & $\begin{array}{l}\text { Patients with LTCs } \\
\text { attending Specialty Clinics } \\
(\mathbf{N}=\mathbf{2 9 2})\end{array}$ \\
\hline $\begin{array}{l}\text { Internal Consistencies } \\
\text { (Cronbach's alphas) }\end{array}$ & 0.89 & 0.91 & 0.91 & 0.88 \\
$\begin{array}{l}\text { RS-14 Total score } \\
\text { (mean } \pm \text { SD) }\end{array}$ & $79.2 \pm 11.7$ & $81.5 \pm 11.9 *$ & $76.8 \pm 9.0 *$ & $78.8 \pm 12.1$ \\
\hline
\end{tabular}

(*) asterisk indicate statistically significant difference at a $\mathrm{p}=0.02 \mathrm{I}$ between healthy participants and ED patients based on one-way analysis of variance with Bonferroni post-hoc tests $\left(\mathrm{F}_{[2,92]}=4.07, \mathrm{p}=0.018\right)$

\section{Discussion}

The results of the present study revealed that the Greek version of RS-14 showed a coherent unidimensional factor structure with remarkable stability across the three samples studied. In terms of the factors' content, all items loadings were similar to its original version. ${ }^{24}$ Internal consistency coefficients were adequate across all samples and all indices of criterion and convergent validity were in the expected direction. Present findings support the validity of the RS14 for use within the Greek population.

Similar to the results of the original version, ${ }^{24,26}$ the present findings showed that a coherent one factor solution of the instrument accounted for $39.4-49.6 \%$ of the variance across the three samples. All items loaded saliently on this factor with all loadings being greater than 0.40 and most of them greater than 0.60 . The lower but still significant loadings (0.41 and 0.43) observed for items 9 ("I keep interested 
in things") and 10 ("I can usually find something to laugh about") in the ED sample, and this could be attributed to the psychological attitude of ED patients who, facing an emergency situation, is not expected to greatly "keep interest in things" or to "find something to laugh about". In line also with the results of numerous previous studies performed this version of RS-14 demonstrated good internal consistency coefficients, with Cronbach's alphas ranging between 0.88 and 0.91 across the three samples, supporting its internal consistency reliability. Studies have reported alphas for RS-14 ranging from 0.72 to $0.94 ;{ }^{27}$ alphas for healthy participants and general population have been found between 0.88 and $0.94,{ }^{26,30} 0.92$ for depressed patients ${ }^{27}$ and 0.93 for medical patients. ${ }^{27,34}$

Table 3 Distribution of RS- I 4 categories across the three samples

\begin{tabular}{|c|c|c|c|c|}
\hline Resilience & $\begin{array}{l}\text { Total } \\
\text { Sample } \\
(\mathbf{N}=495)\end{array}$ & $\begin{array}{l}\text { Participants } \\
\text { without LTCs } \\
(\mathbf{N}=129)\end{array}$ & $\begin{array}{l}\text { Patients with LTCs } \\
\text { attending the Emergency } \\
\text { Department }(\mathrm{N}=74)\end{array}$ & $\begin{array}{l}\text { Patients with LTCs } \\
\text { attending Specialty } \\
\text { Clinics }(\mathbf{N}=\mathbf{2 9 2})\end{array}$ \\
\hline Low $(<64)$ & $56(11.3 \%)$ & II (8.5\%) & $10(13.5 \%)$ & 35 (I2.0\%) \\
\hline $\begin{array}{l}\text { Moderately low } \\
\text { to moderate }(65-8 I)\end{array}$ & 204 (4I.2\%) & 45 (34.9\%) & 38 (5I.4\%) & $12 \mid(4 \mid .4 \%)$ \\
\hline Moderately high (82-90) & $145(29.3)$ & $43(33.3 \%)$ & $20(27.0 \%)$ & $82(28.1 \%)$ \\
\hline High $(>90)$ & $90(18.2 \%)$ & $30(23.3 \%)$ & $6(8.1 \%)$ & $54(18.5 \%)$ \\
\hline
\end{tabular}

Chi square $=7.81, \mathrm{df}=6, \mathrm{p}=0.252$

Table 4 Resilience and mental IIlness in the total sample ( $\mathrm{N}=495)$

\begin{tabular}{|c|c|c|c|c|c|c|c|c|}
\hline \multirow[b]{2}{*}{$\begin{array}{l}\text { RS- I } 4 \text { Total } \\
\text { score }\end{array}$} & \multicolumn{2}{|c|}{ Any Mental Disorder } & \multicolumn{2}{|c|}{ Major Depression } & \multicolumn{2}{|c|}{ Panic Disorder } & \multicolumn{2}{|c|}{ Generalized Anxiety Disorder } \\
\hline & $\begin{array}{l}\text { Yes } \\
(N=201)\end{array}$ & $\begin{array}{l}\text { No } \\
(N=294)\end{array}$ & $\begin{array}{l}\text { Yes } \\
(N=|I|)\end{array}$ & $\begin{array}{l}\text { No } \\
(N=294)\end{array}$ & $\begin{array}{l}\text { Yes } \\
(N=27)\end{array}$ & $\begin{array}{l}\text { No } \\
(N=297)\end{array}$ & $\begin{array}{l}\text { Yes } \\
(N=76)\end{array}$ & $\begin{array}{l}\text { No } \\
(N=294)\end{array}$ \\
\hline $\begin{array}{l}\text { Mean } \pm \text { SD } \\
\text { (Two-tailed } \\
\text { t-tests) }\end{array}$ & $75.2 \pm 12.1$ & $81.9 \pm 10.7 * * *$ & $72.6 \pm 12.9$ & $81.9 \pm 10.7 * * *$ & $73.7 \pm 16.2$ & $81.9 \pm 10.7 * *$ & $74.4 \pm 11.9$ & $81.9 \pm 10.7 * * *$ \\
\hline OR $(95 \% \mathrm{Cl})$ & \multicolumn{2}{|c|}{$0.95(0.933-0.966) * * *$} & \multicolumn{2}{|c|}{$0.93(0.914-0.954) * * *$} & \multicolumn{2}{|c|}{$0.96(0.937-0.992) * *$} & \multicolumn{2}{|c|}{$0.94(0.924-0.967) * * *$} \\
\hline
\end{tabular}

OR, Odds ratio; $\mathrm{Cl}$, Confidence interval; $* * * \mathrm{p}<0.00 \mathrm{I},{ }^{* *} \mathrm{p}<0.0 \mathrm{I}$

Table 5 Resilience and depressive symptom severity, suicidal risk, and health-related quality of life $(H R Q \circ L)(N=495)$

\begin{tabular}{lll}
\hline & \multicolumn{2}{l}{ Resilience (RS- I4) } \\
& \multicolumn{2}{l}{ Correlation Coefficients } \\
& Unadjusted & Adjusted \\
\hline Depressive symptoms (PHQ-9) & $-0.329 * * *$ & $-0.306 * * *$ \\
\hline Suicidal Risk (RASS) & $-0.416 * * *$ & $-0.417 * * *$ \\
\hline HRQoL & & \\
\hline Overall HRQoL & $0.322 * * *$ & $0.330 * * *$ \\
\hline Satisfaction with General Health & $0.290 * * *$ & $0.290 * * *$ \\
\hline Physical HRQoL & 0.37 I *** & 0.35 I*** \\
\hline Mental HRQoL & $0.542 * * *$ & $0.530 * * *$ \\
\hline Social Relations HRQoL & $0.349 * * *$ & $0.298 * * *$ \\
\hline Environment HRQoL & $0.265 * * *$ & $0.274 * * *$ \\
\hline
\end{tabular}

Note: values shown are bivariate Pearson correlation coefficients and partial Pearson correlation coefficients adjusted for age, sex, education, family status, number of medical illness ( 0 for healthy participants) and comorbidities $* * * \mathrm{p}<0.001$, ** $\mathrm{p}<0.01$, * $\mathrm{p}<0.05$

The criterion validity of the RS-14 was supported in three ways. First, people with MDD, panic disorder or GAD presented lower resilience rates compared to those without a mental disorder. RS14 was also negatively related to depressive symptom severity. The resilience approach in mental health research proposes a biopsychosocial model, including components relevant to biological predispositions, personal adaptive and maladaptive re-activities (e.g., coping behaviors), individual psychological development and social factors. ${ }^{54} \mathrm{In}$ this realm, measures of resilience have been found strongly associated with mental health in both general population and physical illness. ${ }^{55-59}$ In line with present findings, the original as well as all other studies performed have also found sound negative correlations between RS-14 and depression, anxiety, stress, and posttraumatic stress measures. ${ }^{5,11,26,27,30}$ By using a structured psychiatric interview for reliably establishing mental diagnoses, our results support the relationship of resilience with mental health further confirming the available evidence.

Second, RS-14 scores were negatively associated with suicidal risk, and these correlations were among the highest negative correlations observed amongst the scales used in the present study. Recent evidence suggests that a wide range of psychological factors link resilience to suicidality, suggesting that psychological resilience should be viewed as a separate dimension which acts to moderate the impact of risk on suicidality. ${ }^{60}$ Low resilience has been found in abstinent substance dependent patients who had attempted suicide,$^{51}$ while patients with systemic lupus erythematosus at risk of committing suicide presented the lowest resilience scores. ${ }^{52}$ It has been also reported that resilience may be a protective factor mitigating the risk of suicidal behavior associated with childhood trauma, ${ }^{50}$ while resilience has been found 
to act as a moderator of lifetime violent events and attempted suicide in adolescents and young adults, even in the presence of antecedent depression. ${ }^{53}$ Our findings further support the link between resilience and suicidality and provide additional evidence with regard to the validity of both RS-14 as well as the newly introduced scale for the assessment of suicidality risk, i.e. the RASS.

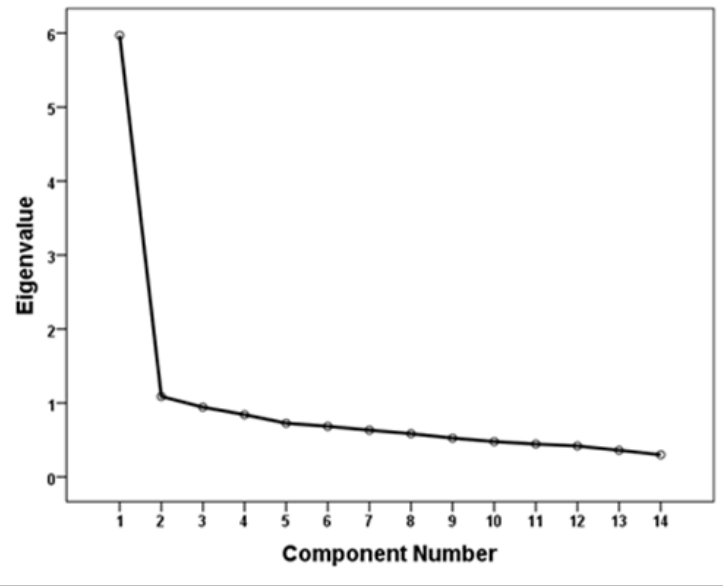

Figure I Screen plot of the eigenvalues of the RS-I4 scores.

Third, higher RS-14 scores were associated with better overall HRQoL and satisfaction with general health as well as with better HRQoL in all dimensions of WHOQOL-BREF, confirming our hypothesis. RS-14 scores have been found correlated with measures of satisfaction with life ${ }^{5}$ and higher resilience levels as measured by the RS-14 have been found associated with a better quality of life as measured by the WHOQOL-BREF. ${ }^{33}$ Also, lower levels of resilience were associated with worse HRQoL in cancer patients, ${ }^{34}$ while a recent systematic review of resilience in the physically ill found that resilience was associated with factors directly salient to physical illness, including HRQoL. ${ }^{57}$

Finally, similar to the original version's study, ${ }^{26}$ resilience tended to increase by age, while the better the physical health the higher the RS-14 scores. On the other hand, we found comparable levels of resilience in men and women. Studies investigating resilience across gender are inconclusive. The original RS-14 study found higher resilience levels among females ${ }^{26}$ and others have found that women were less resilient than men. ${ }^{3,61}$ In a more recent study with two large samples, ${ }^{5}$ males in a clinical sample presented higher levels of resilience than females, while in a college student sample females had higher levels of resilience than men. Other studies have also shown that men demonstrate similar with women levels of resilience following a traumatic event. ${ }^{62}$ It has been pointed out that a response bias may interfere with the observed difference in resilience between males and females, as men may be more concerned with appearing strong. ${ }^{61}$

Strengths of our study include the use of the MINI structured interview for establishing a diagnosis of mental disorder, which was conducted face-to-face with the participant on the same day as the selfreport questionnaires. Also, we used well recognized, standardized instruments for all validity measures, and we recruited patients with established LTCs with a high response rate ( $86 \%)$. Nevertheless, some limitations need to be addressed. It could be argued that a limitation of our study lies in the composition of the "healthy" participant sample, which was recruited from hospital staff and could not be considered representative of the general population. In addition, although mental illness was confirmed by a structured interview, the drawback of using self-report measures for depressive symptom severity, suicidality and
HRQoL means that we cannot refute the criticism that an underlying response style might have intervened with the results. Finally, the cross-sectional design of the current study precluded the establishment of causal inferences.

In conclusion, the results of the present study showed that the Greek version of the RS-14 presents a coherent unidimensional structure. Internal consistencies were adequate and concurrent and convergent validity quite satisfactory. These findings support the applicability of the Greek version of RS-14 within the Greek population, and future studies could further explore the relevance of RS-14 with additional scales and outcomes as well as its predictive validity. Importantly, in patients with chronic physical illnesses, the study of additional psychological factors building resilience such as optimism, social support, or illness perceptions ${ }^{57}$ and their complex interplay could shed more light in our understanding of the specific paths that form patients' outcome and this may have important clinical implications as far as adaptation to medical illness is concerned.

\section{Acknowledgements}

The project "ASSessing and Enhancing Resilience To DEPression in people with long term medical conditions in the era of the current Greek social and financial crisis (ASSERT-DEP)" has been co-financed by the European Economic Area (EEA) Financial Mechanism 20092014 (EEA GR07/3767) and National funds as part of the program "Dissimilarity, Inequality and Social Integration" (Grant number: 132324/I4-25/8/2015). The funding source had no involvement in study design; in the collection, analysis and interpretation of data; in the writing of the report; and in the decision to submit the article for publication.

AFC is supported by a research scholarship award from the Conselho Nacional de Desenvolvimento Científico e Tecnológico (CNPq; Brazil).

ASSERT-DEP Study Group members are: Katerina Antoniou, Petros Bozidis, Andre F. Carvalho, Foteini Delis, Alexandros A. Drosos, Elspeth Guthrie, Stavros Constantopoulos, Elisavet Ntountoulaki, Vassiliki Paika, Nafsika Poulia, Marianthi Sotiropoulou, Vasilis Tsimihodimos and Thomas Hyphantis (Principal Investigator).

\section{Declarations}

\section{Ethics approval and consent to participate}

I. All study procedures were in accordance with the World Medical Association Helsinki Declaration.

II. The study was approved by the Ioannina Teaching General Hospital hospital's ethics committee (617/17-09-2015).

III. Signed informed consent was obtained from all participants.

\section{Authors' contributions}

All authors were involved in drafting the article or revising it critically for important intellectual content, and all authors approved the final version to be submitted for publication. TH had full access to all of the data in the study and takes responsibility for the integrity of the data and the accuracy of the data analysis. TH, VP, EN and AC were involved in study conception and design. VP, EN, DP and KK were involved in acquisition of data. TH, VP, EN, EA, KF, and AC were involved in analysis and interpretation of data.

\section{Conflicts of interest}

Author declares there are no conflicts of interest. 


\section{Funding}

None.

\section{References}

1. Park CL, Slattery JM. Resilience interventions with a focus on meaning and values. In Kent M, et al. (Eds.), the resilience handbook: Approaches to stress and trauma. Routledge, New York, USA. 2014. p.270-282.

2. Zakour MJ. Coping with loss and overcoming trauma. In Framingham JL \& Teasley ML (Eds.), Behavioral health response to disasters Boca Raton, CRC, FL, USA. 2012. p. 91-113.

3. Bonanno GA. Loss, trauma, and human resilience: have we underestimated the human capacity to thrive after extremely aversive events? Am Psychol. 2004;59(1):20-28.

4. Halpern J, Tramontin M. Disaster mental health: Theory and practice. Brooks/Cole, Belmont, CA, USA. 2007.

5. Aiena BJ, Baczwaski BJ, Schulenberg SE, et al. Measuring resilience with the RS-14: a tale of two samples. J Pers Assess. 2015;97(3):291-300.

6. Windle G. What is resilience? A review and concept analysis. Rev Clin Gerontol. 2011;21(2):152-169.

7. Hjemdal O. Measuring protective factors: the development of two resilience scales in Norway. Child Adolesc Psychiatr Clin N Am. 2007; 16(2):303-321.

8. Wong PTP, Wong LCJ. A meaning-centered approach to building youth resilience. In PTP Wong (Ed.), The human quest for meaning: Theories, research, and applications (2nd edn.), Routledge, New York, USA. 2004. p.585-617.

9. Greve W, Staudinger UM. Resilience in later adulthood and old age: Resources and potentials for successful aging. John Wiley \& Sons, USA. 2015 .

10. Abiola T, Udofia O. Psychometric assessment of the Wagnild and Young's resilience scale in Kano, Nigeria. BMC Res Notes. 2011;4:509.

11. Damásio BF, Borsa JC, Da Silva JP. 14-item resilience scale (RS14): psychometric properties of the Brazilian version. J Nurs Meas. 2011;19(3):131-145.

12. Baldwin DR, Jackson D, Okoh I, et al. Resiliency and optimism: An African American senior citizen's perspective. J Black Psychol. 2011;37(1):24-41.

13. Fredrickson BL, Tugade MM, Waugh CE, et al. What good are positive emotions in crisis? A prospective study of resilience and emotions following the terrorist attacks on the United States on September 11th, 2001. J Pers Soc Psychol. 2003;84(2):365-376.

14. Scali J, Gandubert C, Ritchie K, et al. Measuring resilience in adult women using the 10-items Connor- Davidson Resilience Scale (CDRISC): Role of trauma exposure and anxiety disorders. PLoS One. 2012;7(6):e39879.

15. Tugade MM, Fredrickson BL. Resilient individuals use positive emotions to bounce back from negative emotional experiences. J Pers Soc Psychol. 2004;86(2):320-333.

16. Costa AL, Heitkemper MM, Alencar GP, et al. Social Support Is a Predictor of Lower Stress and Higher Quality of Life and Resilience in Brazilian Patients With Colorectal Cancer. Cancer Nurs. 2016.

17. Li MY, Yang YL, Liu L, et al. Effects of social support, hope and resilience on quality of life among Chinese bladder cancer patients: a cross-sectional study. Health Qual Life Outcomes. 2016;14:73.

18. Li M, Wang L. The Associations of Psychological Stress with Depressive and Anxiety Symptoms among Chinese Bladder and Renal Cancer Patients: The Mediating Role of Resilience. PloS One. 2016;11(4):e0154729.
19. Connor KM, Davidson JR. Development of a new resilience scale: The Connor-Davidson resilience scale (CD-RISC). Depress Anxiety. $2003 ; 18(2): 76-82$.

20. Hurtes KP, Allen LR. Measuring resiliency in youth: The resiliency attitudes and skills profile. Therap Recreat J. 2001;35(4):333-347.

21. Friborg O, Hjemdal O, Rosenvinge JH, et al. A new rating scale for adult resilience: What are the central protective resources behind healthy adjustment? Int J Methods Psychiatr Res. 2003;12(2):65-76.

22. Smith BW, Dalen J, Wiggins K, et al. The brief resilience scale: assessing the ability to bounce back. Int J Behav Med. 2008;15(3):194-200.

23. Windle G, Bennett KM, Noyes J. A methodological review of resilience measurement scales. Health Qual Life Outcomes. 2011;9:8.

24. Wagnild GM, Young HM. Development and psychometric evaluation of the Resilience Scale. J Nurs Meas. 1993;1(2):165-178.

25. Ahern NR, Kiehl EM, Sole ML, et al. A review of instruments measuring resilience. Issues Compr Pediatr Nurs. 2006;29(2):103-125.

26. Wagnild GM. The Resilience Scale: User's guide guide for the US English version of the Resilience Scale and the 14-item Resilience Scale ver. 3.33. Resilience Center, Montana, USA. 2016.

27. Wagnild G. A review of the Resilience Scale. J Nurs Meas. 2009;17:105-113.

28. Wagnild G, Young HM. Resilience among older women. Image J Nurs Sch. 1990;22(4):252-255.

29. Wagnild GM. Resilience Scale - A Reliable and Valid tool to Measure Resilience. 2009.

30. Nishi D, Uehara R, Kondo $\mathrm{M}$, et al. Reliability and validity of the Japanese version of the Resilience Scale and its short version. BMC Res Notes. 2010;3:310.

31. Yang Y, Li M, Xia Y. Measurement invariance of the Resilience Scale. Int J Educ Psychol Ass. 2012;11:1-19.

32. Kwon HJ, Kwon SJ. Korean Version of the 14-Item Resilience Scale (RS-14) for University Students: A Validity and Reliability Study. J Korean Acad Psychiat Mental Health Nurs. 2014;23(4):226-232.

33. Tempski P, Santos IS, Mayer FB, et al. Relationship among Medical Student Resilience, Educational Environment and Quality of Life. PLoS One. 2015;10(6): $\mathrm{e} 0131535$.

34. Tian J, Hong JS. Validation of the Chinese version of the resilience scale and its cutoff score for detecting low resilience in Chinese cancer patients. Support Care Cancer . 2013;21(5):1497-1502.

35. Panicker AS, Chelliah A. Resilience and Stress in Children and Adolescents with Specific Learning Disability. J Can Acad Child Adolesc Psychiatry. 2016;25(1):17-23.

36. Pritzker S, Minter A. Measuring adolescent resilience: An examination of the cross-ethnic validity of the RS-14. Child Youth Serv Rev. 2014;44:328-333.

37. Nawar EW, Niska RW, Xu J. National Hospital Ambulatory Medical Care Survey: 2005 emergency department summary. Adv Data. 2007;386:1-32.

38. Damush TM, Smith DM, Perkins AJ, et al. Risk Factors for Nonelective Hospitalization in Frail and Older Adult, Inner-City Outpatients. Gerontologist. 2004;44(1):68-75.

39. Charlson ME, Pompei P, Ales KL, et al. A new method of classifying prognostic Comorbidity in longitudinal studies: development and validation. J Chronic Dis. 1987; 40(5):373-383.

40. Papadimitriou GN, Beratis S, Matsoukas T, et al. The Greek translation of the Mini International Neuropsychiatric Interview MINI 5.0.0. Dept of Psychiatry of the University of Athens and Patras, Greece. 2004. 
41. Sheehan DV, Lecrubier Y, Harnett-Sheehan K, et al. The Mini International Neuropsychiatric Interview (M.I.N.I.): the development and validation of a structured diagnostic psychiatric interview for DSMIV and ICD-10. J Clin Psychiatry. 1998;59(Suppl 20):22-33.

42. Hyphantis T, Kotsis K, Voulgari PV, et al. Diagnostic accuracy, internal consistency, and convergent validity of the Greek version of the patient health questionnaire 9 in diagnosing depression in rheumatologic disorders. Arthritis Care Res. 2011;63(9):1313-1321.

43. Hyphantis T, Kroenke K, Papatheodorou E, et al. Validity of the Greek version of the PHQ 15-item Somatic Symptom Severity Scale in patients with chronic medical conditions and correlations with emergency department use and illness perceptions. Compr Psychiatry. 2014;55(8):1950-1959.

44. Hyphantis T, Kotsis K, Kroenke K, et al. Lower PHQ-9 cut poin accurately diagnosed depression in people with long-term conditions attending the Accident and Emergency Department. J Affect Disord. 2015;176:155-163.

45. Wittkampf KA, Naeije L, Schene AH, et al. Diagnostic accuracy of the mood module of the Patient Health Questionnaire: a systematic review. Gen Hosp Psychiatry. 2007; 29(5):388-395.

46. Fountoulakis KN, Pantoula E, Siamouli M, et al. Development of the Risk Assessment Suicidality Scale (RASS): a population-based study. $J$ Affect Disord. 2012;138(3):449-457.

47. Ntountoulaki E, Guthrie E, Kotsis K, et al. Double RASS cut point accurately diagnosed suicidal risk in females with long-term conditions attending the emergency department compared to their male counterparts. Compr Psychiatry. 2016;69:193-201.

48. Ginieri-Coccossis M, Triantafillou E, Tomaras V, et al. Psychometric properties of WHOQOL-BREF in clinical and health Greek populations: incorporating new culture relevant items. Psychiatriki. 2012;23(2):130-142.

49. Altman DG. Practical statistics for medical research, Chapman and Hall, London, UK. 1991. p. 285.

50. Roy A, Carli V, Sarchiapone M. Resilience mitigates the suicide risk associated with childhood trauma. J Affect Disord. 2011;133(3): $591-594$.
51. Roy A, Sarchiapone M, Carli V. Low resilience in suicide attempters. Arch Suicide Res. 2007;11(3):265-269.

52. Cal SF, Santiago MB. Resilience in systemic lupus erythematosus. Psychol Health Med. 2013;18(5):558-563.

53. Nrugham L, Holen A, Sund AM. Associations between attempted suicide, violent life events, depressive symptoms, and resilience in adolescents and young adults. J Nerv Ment Dis. 2010;198(2):131-136.

54. Davydov DM, Stewart R, Ritchie K, et al. Resilience and mental health. Clin Psychol Rev. 2010;30(5):479-495.

55. Ryff CD. Psychological well-being revisited: advances in the science and practice of eudaimonia. Psychother Psychosom. 2014;83(1):10-28.

56. Macedo T, Wilheim L, Gonçalves R, et al. Building resilience for future adversity: a systematic review of interventions in non-clinical samples of adults. BMC Psychiatry . 2014;14:227.

57. Stewart DE, Yuen T. A systematic review of resilience in the physically ill. Psychosomatics. 2011;52(3):199-209.

58. Peng L, Zhang J, Li M, et al. Negative life events and mental health of Chinese medical students: the effect of resilience, personality and social support. Psychiatry Res. 2012;196(1):138-141.

59. Min JA, Jung YE, Kim DJ, et al. Characteristics associated with low resilience in patients with depression and/or anxiety disorders. Qual Life Res. 2013;22(2):231-341.

60. Johnson J, Wood AM, Gooding P, et al. Resilience to suicidality: the buffering hypothesis. Clin Psychol Rev. 2011;31(4):563-591.

61. Campbell-Sills L, Forde DR, Stein MB. Demographic and childhood environmental predictors of resilience in a community sample. $J$ Psychiatr Res. 2009;43(12):1007-1012.

62. Morano C. Resilience and coping with trauma: Does gender make a difference? J Hum Beh Soc Environ. 2010;20(4):553-568. 